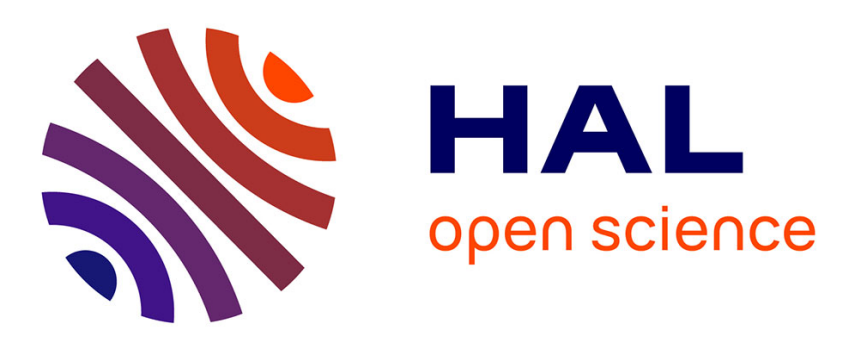

\title{
The effect of acute hypoxia on swimming stamina at optimal swimming speed in flathead grey mullet Mugil cephalus
}

Marie Vagner, Christel Lefrançois, Sylvana Ferrari, Andrea Satta, Paolo Domenici

\section{To cite this version:}

Marie Vagner, Christel Lefrançois, Sylvana Ferrari, Andrea Satta, Paolo Domenici. The effect of acute hypoxia on swimming stamina at optimal swimming speed in flathead grey mullet Mugil cephalus. Marine Biology, 2008, 155 (2), pp.183 - 190. 10.1007/s00227-008-1016-x . hal-01455041

\section{HAL Id: hal-01455041 https://hal.science/hal-01455041}

Submitted on 3 Feb 2017

HAL is a multi-disciplinary open access archive for the deposit and dissemination of scientific research documents, whether they are published or not. The documents may come from teaching and research institutions in France or abroad, or from public or private research centers.
L'archive ouverte pluridisciplinaire HAL, est destinée au dépôt et à la diffusion de documents scientifiques de niveau recherche, publiés ou non, émanant des établissements d'enseignement et de recherche français ou étrangers, des laboratoires publics ou privés. 


\title{
The effect of acute hypoxia on swimming stamina at optimal swimming speed in flathead grey mullet Mugil cephalus
}

\author{
M. Vagner $\cdot$ C. Lefrançois $\cdot$ R. S. Ferrari \\ A. Satta $\cdot$ P. Domenici
}

Received: 5 March 2008/ Accepted: 9 June 2008/Published online: 8 July 2008

(C) Springer-Verlag 2008

\begin{abstract}
Flathead grey mullets Mugil cephalus are commonly found in Mediterranean lagoons, which are regularly subject to high environmental variations. Oxygen is one of the factors that shows extremely high variation. The objective of this study was to test the effects of acute hypoxia exposure at two experimental temperatures (i.e. 20 and $30^{\circ} \mathrm{C}$ ) on the stamina (time to fatigue) in M. cephalus swimming at the minimal cost of transport (i.e. optimal swimming speed; $U_{\text {opt }}$ ). At each temperature, a relationship was established between swimming speed and oxygen consumption $\left(\mathrm{MO}_{2}\right)$. This allowed estimation of $U_{\mathrm{opt}}$ at $45 \mathrm{~cm} \mathrm{~s}^{-1}\left(\sim 1.12\right.$ Body Length $\left.\mathrm{s}^{-1}\right)$. Independent of temperature, stamina at $U_{\text {opt }}$ was significantly reduced in severe hypoxia, i.e. at $15 \%$ of air saturation (AS). In these conditions, oxygen supply appears therefore to be insufficient to maintain swimming, even at the low speed tested
\end{abstract}

Communicated by H.O. Pörtner.

M. Vagner · C. Lefrançois · R. S. Ferrari

A. Satta $\cdot$ P. Domenici

IMC-International Marine Centre, Loc. Sa Mardini,

09072 Torregrande, Oristano, Italy

Present Address:

M. Vagner

Department PFOM, UMR 1067, Ifremer Plouzané, France

C. Lefrançois $(\square)$

LIENSS (UMR 6250 : CNRS/University La Rochelle) 2,

rue Olympe de Gouges, 17000 La Rochelle, France

e-mail: clefranc@univ-lr.fr

C. Lefrançois · P. Domenici

CNR-IAMC, Loc. Sa Mardini, 09072 Torregrande,

Oristano, Italy here. After the stamina test, $\mathrm{MO}_{2}$ measured in fish tested at $15 \%$ AS was significantly higher than that measured after the test in normoxia. Therefore, we suggest that in hypoxia, fish used anaerobic metabolism to supplement swimming at $U_{\text {opt }}$, leading to an oxygen debt. Since flathead grey mullet is a hypoxia-tolerant species, it is possible that hypoxic conditions less severe than those tested here may reduce stamina at low speed in less tolerant species. In addition, we suggest that testing stamina at these speeds may be relevant in order to understand the effect of hypoxia on behavioural activities carried out at low speed, such as food searching.

\section{Introduction}

Previous work on fish swimming has mainly focused on maximum performance. Maximum swimming performance varies with intrinsic factors, such as size, shape, physiological status (Webb 1977; Videler 1993; Domenici and Blake 1993; Ghalambor et al. 2004) and with environmental factors, such as temperature and oxygen (Kutty 1968; Bushnell et al. 1984; Lee et al. 2003a; Lefrançois et al. 2005). The effect of environmental factors on maximum swimming performance is highly relevant for a number of situations, such as river migration, dam overpassing or predator-prey relationships involving chases or attacks (for reviews Videler 1993; Domenici et al. 2007; Claireaux and Lefrançois 2007). While maximum speeds have been extensively investigated both in terms of anaerobic (burst) and aerobic (sustained) swimming, very little is known on the factors affecting slow swimming speeds and the relative stamina. The ability of fish to sustain relatively slow swimming speeds, however, 
represents equally important survival values since these speeds are used by fish in their routine activities, such as searching for food and habitat exploration (Videler 1993). During such routine activities, the behaviour of fish may be optimized by swimming at a speed that implies the lowest amount of energy per unit travelled ( $U_{\text {opt}}$; Tucker 1970; Weihs 1973).

$U_{\text {opt }}$ is defined by means of the relationships between oxygen consumption and swimming speed which is typically exponential (Brett 1964; Webb 1975; Thorarensen et al. 1993; Gallaugher et al. 2001). Therefore, when expressed for each swimming speed, the energetic cost of transport (COT) per unit distance leads to a U-shaped curve with a minimum at $\mathrm{U}_{\mathrm{opt}}$ that was often found to be around 1-2 Body Length $\mathrm{s}^{-1}$ (BL s$^{-1}$ ) (Brett 1965; Webb 1975; Videler 1993). All energy-demanding activities (e.g. swimming, digestion, growth) of an animal must be accommodated within its aerobic metabolic scope (AMS; Fry 1971; Claireaux and Lefrançois 2007). Therefore, higher AMS or lower costs of activities participate to a reduction of energy budgeting conflicts between competing demands or functions. It has been suggested that swimming at $U_{\text {opt }}$ may minimize cost of transport in order to save energy which can be allocated to other activities such as somatic and/or gonadic growth (Videler 1993; Hinch and Rand 2000).

Flathead grey mullet (Mugil cephalus) is a benthic feeder that mainly feeds on organic matter of the superficial mudflat or on microphytobenthos and that spends a high proportion of its day swimming to forage (Domenici and Lefrançois, personal observations). The importance of the searching phase and the associated energy expenses is likely to be high in comparison to sit-and-wait predators. Therefore, swimming at $U_{\text {opt }}$ may be particularly beneficial to this species. Flathead grey mullets live in highly variable environments, with large fluctuations in temperature, oxygen and salinity. Hypoxia is known to affect antipredator behaviour in M. cephalus (Shingles et al. 2005). However, little is known on the effects of hypoxia on the sustained swimming performance of this species. Using $U_{\mathrm{opt}}$ as an ecologically relevant speed for the routine activity of $M$. cephalus, we hypothesized that hypoxia will induce (1) a reduction of the swimming stamina at this speed and (2) a solicitation of the anaerobic metabolism revealed by post-exercise oxygen consumption. In order to test these hypotheses, we measured the time to fatigue of M. cephalus swimming at $U_{\text {opt }}$ while exposed at various oxygen levels at 20 and $30^{\circ} \mathrm{C}$, i.e. a typical spring and summer temperature, respectively. Swimming performance of $M$. cephalus and associated energetic costs were measured using a swimming respirometer, where individuals were tested at a constant speed or following a step-protocol.

\section{Material and methods}

Fish maintenance

Flathead grey mullets [mean weight \pm standard error (s.e.): $491.3 \pm 128.1 \mathrm{~g}$ ranging from 417.7 to $624.9 \mathrm{~g}$; mean length \pm s.e.: $39.5 \pm 3.3 \mathrm{~cm}$ ranging from 38.0 to $42.8 \mathrm{~cm}$ ] were caught in a local lagoon (Cabras, Sardinia, Italy) during 2003-2004 and transferred to outdoor basins (length: $10 \mathrm{~m}$, width: $4 \mathrm{~m}$, depth: $1.5 \mathrm{~m}$ ) with recirculated water from the lagoon. Because of the annual temperature variations in the lagoon, experiments at 20 and $30^{\circ} \mathrm{C}$ were performed during spring and summer 2004, respectively. At least two weeks before the beginning of the experiment, fish were transferred from these outdoor tanks to indoor circular tanks (diameter: $2 \mathrm{~m}$, depth: $1 \mathrm{~m}$ ) with recirculated and filtered natural seawater where they were acclimated to the experimental conditions (temperature range: $20 \pm 1$ and $30 \pm 1^{\circ} \mathrm{C}$; salinity range: $27 \pm 1$ and $28 \pm 2 \%$ for experiments at 20 and $30^{\circ} \mathrm{C}$, respectively). Values of these parameters were monitored each day with a conductimeter (WTW model cond 315i). Fish were fed twice a week on cheese powder (Blu Marlin) and were starved for at least $48 \mathrm{~h}$ before being transferred to the swim-tunnel respirometer where their swimming performances were tested.

\section{Experimental set-up}

The swim-tunnel-respirometer (Swim-90 Loligo, Denmark) was equipped with an external bath where the temperature and the oxygenation of the water were controlled. The respirometer (volume: $85 \mathrm{~L}$ ) was composed of (1) a swim chamber with a square working section $(20 \mathrm{~cm}$ width and $64 \mathrm{~cm}$ of length) and (2) a hydraulic system placed upstream to generate a laminar flow in the swim chamber. The hydraulic system is composed by honeycomb materials and half-circle shaped sections that distribute water flow in the working section. No correction for solid blocking effects of the fish in the working section was made since the fish cross-section was $<5 \%$ of the working section area (Webb 1975). The flow in the respirometer was generated by an electric thruster motor with a propeller. The flow was manually controlled through a controller instrument connected to the thruster motor. A voltmeter allowed recording analog output voltage from the motor controller instrument. The relationships between analog output and water speed in the swim tunnel were previously established using a flow meter (Höntzsch, Germany). Water oxygenation was regulated by recirculating water from the external bath in a counter-current gas equilibration column bubbled with (1) air to maintain normoxia or (2) nitrogen to establish hypoxic conditions. 
Oxygen concentration in the external bath was measured with an oxygen measuring system (WTW Oxi 340i) connected to a computer storing data every $5 \mathrm{~s}$. Temperature was kept constant by recirculating water from the external bath through a cooling system (TECO CA 240). A flush pump allowed exchange of water between the external bath and the respirometer.

\section{Oxygen consumption measurements}

During the experiments, a continuous flow of water was pumped from the respirometer to a flow-through cuvette and back to the respirometer. An oxygen probe (WTW CellOx 125) was placed in the cuvette and was connected to an oxymeter (WTW oxi 340i) connected to a data logger interface (Labpro Vernier) transferring oxygen data every $2 \mathrm{~s}$ to a storing computer. Oxygen consumption $\left(\mathrm{MO}_{2}\right)$ was measured by intermittent-flow respirometry, based on an alternation between (1) a flushing phase and (2) a measuring phase, during which the flush pump was turned off preventing the inflow of water from the external bath to the respirometer. The oxygen consumption $\mathrm{MO}_{2}$ $\left(\mathrm{mgO}_{2} \mathrm{~kg}^{-1} \mathrm{~h}^{-1}\right)$ was calculated as in Lefrançois and Claireaux (2003):

$\mathrm{MO}_{2}=\frac{\Delta \mathrm{O}_{2}}{\Delta t} \times \frac{V}{m}$

where $\Delta \mathrm{O}_{2}$ is the oxygen concentration decrease relative to the fish oxygen consumption, $\Delta t$ the measuring period, $V$ the volume of the respirometer chamber (85 1) minus volume of the fish and $m$, the fish weight.

For each measure, a linear regression was adjusted in order to determine $\Delta \mathrm{O}_{2} / \Delta t$ from a relationship of $\Delta \mathrm{O}_{2}$ versus time. The regression coefficient of the linear relationships (i.e. $r^{2}$ ), which determined the accuracy of the $\mathrm{MO}_{2}$ measurement, was $>0.7$ in all cases. As the respiratory metabolism depends on the animal weight, $\mathrm{MO}_{2}$ was standardised for a 1-kg fish using the following relation (Lefrançois and Claireaux 2003):

$\mathrm{MO}_{2 \text { cor }}=\mathrm{MO}_{2} \times\left(\frac{m}{m_{\text {cor }}}\right)^{1-A}$

where $\mathrm{MO}_{2 \text { cor }}\left(\mathrm{mgO}_{2} \mathrm{~kg}^{-1} \mathrm{~h}^{-1}\right)$ is the oxygen consumption for a corrected weight, $m_{\mathrm{cor}}$, (i.e. $1 \mathrm{~kg}$ ), $\mathrm{MO}_{2}$ is the measured $\mathrm{MO}_{2}\left(\mathrm{mgO}_{2} \mathrm{~kg}^{-1} \mathrm{~h}^{-1}\right)$ and $\mathrm{m}$ is the fish weight $(\mathrm{kg})$. The coefficient $A$ is the allometric exponent describing the relation between the metabolic rate and the fish weight. A value of 0.8 estimated in some teleosts was used (Schurmann and Steffensen 1994). The bacterial $\mathrm{MO}_{2}$ was measured during half an hour after each experiment and was subtracted from the $\mathrm{MO}_{2}$ measured.
Experimental protocol

Fish were anaesthetised (0.04 $\mathrm{g} \mathrm{l}^{-1}$ of MS-222) and transferred from the indoor acclimation tank to the swim chamber of the respirometer where the water flow was stabilised at a low speed $\left(15 \mathrm{~cm} \mathrm{~s}^{-1}\right)$. In order to motivate the fish to occupy a steady upstream position, a screen darkening the upstream part of the swim chamber was placed. The fish were allowed to recover from the transfer during the following night (photoperiod $14 \mathrm{~h}: 10 \mathrm{~h}$ light:dark cycle).

Determination of $U_{\mathrm{opt}}$ at 20 and $30^{\circ} \mathrm{C}$

\section{Step-protocol}

At each experimental temperature (i.e. 20 and $30^{\circ} \mathrm{C}$ ), fish (number of replicates $N=8$ ) were exposed to a step-protocol to estimate $U_{\text {opt }}$. The step-protocol began after the full night of recovery following the transfer and consisted in progressive water swimming speed increments of $30 \mathrm{~cm} \mathrm{~s}^{-1}$ over $5 \mathrm{~min}$. At each step, the velocity was maintained for $20 \mathrm{~min}$. The respirometer was then hermetically isolated from the external bath by turning off the flushing pump and the oxygen consumption measurement started. During the phase of swimming speed increment, i.e. between two consecutive swimming steps, the water of the respirometer was renewed through the flush pump reactivation in order to keep normoxic conditions, i.e. $>85 \%$ air saturation (AS). The speed increments were repeated until the fish fatigued. Fish were considered fatigued when they were not able to swim away from the grid placed at the rear of the swim chamber after having been stimulated three times. The stimulation was done by lighting up (with a $150 \mathrm{~W}$ spotlight) the rear part of the chamber, which created a high contrast with the shadow part in the front. At the end of the step-protocol, the speed was progressively decreased to $15 \mathrm{~cm} \mathrm{~s}^{-1}$. After each stepprotocol, fish were removed from the swim chamber, anaesthetised with MS-222 $\left(0.1 \mathrm{~g} \mathrm{l}^{-1}\right)$, weighed and measured. They were then transferred to outdoor tanks.

\section{Calculation of $U_{o p t}$}

The total COT $\left(\mathrm{mgO}_{2} \mathrm{~kg}^{-1} \mathrm{~cm}^{-1}\right)$ was calculated with the following relation for each swimming speed at both 20 and $30^{\circ} \mathrm{C}$ :

$\mathrm{COT}=\frac{\mathrm{MO}_{2}}{U}$

where $\mathrm{MO}_{2}$ is the oxygen consumption $\left(\mathrm{mgO}_{2} \mathrm{~kg}^{-1} \mathrm{~s}^{-1}\right)$ and $U$ is the swimming speed $\left(\mathrm{cm} \mathrm{s}^{-1}\right)$. 
$U_{\text {opt }}$ was defined as the swimming speed at which the mean COT was minimum.

Stamina test at $U_{\text {opt }}$ at four oxygen levels set at 20 and $30^{\circ} \mathrm{C}$

At each experimental temperature (i.e. 20 and $30^{\circ} \mathrm{C}$ ), 28 fish were used to test the effect of hypoxia on the swimming stamina at $U_{\text {opt }}$ (i.e. 7 different fish were tested at each of the four oxygen treatments).

In normoxia ( $>85 \% \mathrm{AS}$ ), the speed was progressively increased from $15 \mathrm{~cm} \mathrm{~s}^{-1}$ to $U_{\text {opt }}$ (over a 5-min period) after the full night of recovery following the transfer. When $U_{\text {opt }}$ was reached, the speed was stabilised and the test started $\left(t_{0}\right)$.

For hypoxia treatments, the oxygen level was progressively decreased (about $1 \%$ per minute) after the full night of recovery following the transfer. The desired oxygen value $(50,25$ or $15 \%$ AS) was then maintained during all the experiment. The fish were allowed to adapt to the hypoxic conditions during $30 \mathrm{~min}$ before progressively increasing the speed. The stamina test began $\left(t_{0}\right)$ when $U_{\text {opt }}$ was reached.

For the stamina test at $U_{\text {opt }}$ (in normoxia and hypoxia), fish were allowed to swim for $165 \mathrm{~min}$. If the fish fatigued before the end of the 165-min period, the test ended $\left(t_{1}\right)$. The criteria of fatigue were the same as those described for the step-protocol. Stamina (i.e. time to fatigue) at $U_{\text {opt }}$ was defined as the time interval between $t_{0}$ and $t_{1}\left(S_{U_{\text {opt }}}\right)$. At $t_{1}$, the swimming speed was reduced to $15 \mathrm{~cm} \mathrm{~s}^{-1}$ and the oxygen concentration was stabilised to normoxia $(>85 \%$ AS). The post-exercise oxygen consumption $\left(\mathrm{MO}_{2}\right)$ was then measured during $120 \mathrm{~min}$ following a flushing:measuring cycle of 15:15 min and four measurements were obtained $\left(\mathrm{MO}_{2-1}, \mathrm{MO}_{2-2}, \mathrm{MO}_{2-3}\right.$ and $\left.\mathrm{MO}_{2-4}\right)$.

After stamina test at $U_{\text {opt }}$, fish were removed from the swim chamber, anaesthetised with MS-222 (0.1 $\left.\mathrm{g} \mathrm{l}^{-1}\right)$, weighed, and measured. They were then transferred to outdoor tanks.

\section{Statistical analysis}

Temperature and oxygen effects on $S_{U_{\text {opt }}}$ were tested using a two-way ANOVA. A repeated-measured (RM) ANOVA was employed on the $\mathrm{MO}_{2}$ recorded after $t_{1}$, at the end of the stamina test, $\left(\mathrm{MO}_{2-1}, \mathrm{MO}_{2-2}, \mathrm{MO}_{2-3}\right.$ and $\left.\mathrm{MO}_{2-4}\right)$ with the recovery time as a within factor, the oxygen and the temperature as between factors. Significance was accepted at $P<0.05$. When significant effect was found, a post hoc test was employed to carry out multiple comparisons. As recommended by Underwood (1981) and Quinn and Keough (2002), when significant interaction was found between the factors tested, a planned comparison was employed (p.c. in the text) to test the statistical significance of specific differences in the statistical analysis design. When no interaction was found, an a posteriori Dunnett test was applied for further analysis to compare normoxia (i.e. control conditions) with each of the hypoxic treatments.

\section{Results}

Determination of the cost of transport (COT) and optimal swimming speed $\left(U_{\text {opt }}\right)$

The relationships between $\mathrm{MO}_{2}$ and swimming speed are shown in Fig. $1 \mathrm{a}\left(20^{\circ} \mathrm{C}\right)$ and Fig. $2 \mathrm{a}\left(30^{\circ} \mathrm{C}\right)$. As swimming speed increased, $\mathrm{MO}_{2}$ increased until it reached a plateau at $\sim 105$ and $\sim 75 \mathrm{~cm} \mathrm{~s}^{-1}$ at 20 and $30^{\circ} \mathrm{C}$, respectively. Exponential curves were fitted between $\mathrm{MO}_{2}$ and swimming speed before that plateau was attained (i.e. between $15-105$ and $15-75 \mathrm{~cm} \mathrm{~s}^{-1}$ at 20 and $30^{\circ} \mathrm{C}$, respectively). Extrapolating these curves beyond these upper speed limits yielded values of estimated $\mathrm{MO}_{2}\left(1,127 \mathrm{mg} \mathrm{O}_{2} \mathrm{~kg}^{-1} \mathrm{~h}^{-1}\right.$ at $135 \mathrm{~cm} \mathrm{~s}^{-1}$ and $478 \mathrm{mg} \mathrm{O}_{2} \mathrm{~kg}^{-1} \mathrm{~h}^{-1}$ at $105 \mathrm{~cm} \mathrm{~s}^{-1}$ for 20 and $30^{\circ} \mathrm{C}$, respectively), that were about twice those obtained experimentally. This suggests that the increase in swimming speed was anaerobically supplemented at these high speeds. The minimal COT calculated using Eq. (3) was therefore chosen among the range of values showing an exponential increase, i.e. the range that should correspond to aerobic swimming activity. At both temperatures, $U_{\mathrm{opt}}$ was found to be $45 \mathrm{~cm} \mathrm{~s}^{-1}$ ( $\sim 12 \mathrm{BL} \mathrm{s}^{-1}$, Fig. 1b, 2b).

Effect of temperature and hypoxia on stamina at $U_{\text {opt }}\left(S_{U_{\text {opt }}}\right)$

No significant difference in $S_{U_{\text {opt }}}$ was observed between 20 and $30^{\circ} \mathrm{C}$-acclimated fish (Fig. 3; two-way ANOVA: $d f=1, F=0.1, P>0.05)$. On the other hand, oxygen had a significant effect on $S_{U_{\text {opt }}}$ (two-way ANOVA: $d f=3$, $F=35.1, P<0.001$ ) regardless of temperature (no interaction effect; two-way ANOVA: $d f=3, \quad F=1.2$, $P>0.05)$. Post hoc test revealed that exposure to $15 \%$ AS significantly reduced $S_{U_{\text {opt }}}$ compared to normoxia (Dunnett test: $d f=49, P<0.01)$, while there was no significant difference between normoxia and the other oxygen treatments (Dunnett test: $d f=49, P>0.05$ for each comparison).

\section{Post-exercise oxygen consumption}

Post-exercise oxygen consumption was found to be dependent on (1) the temperature, (2) the oxygen level at which the fish swam during the stamina test and (3) the recovery time following this test (Table 1 ). $\mathrm{MO}_{2}$ was 

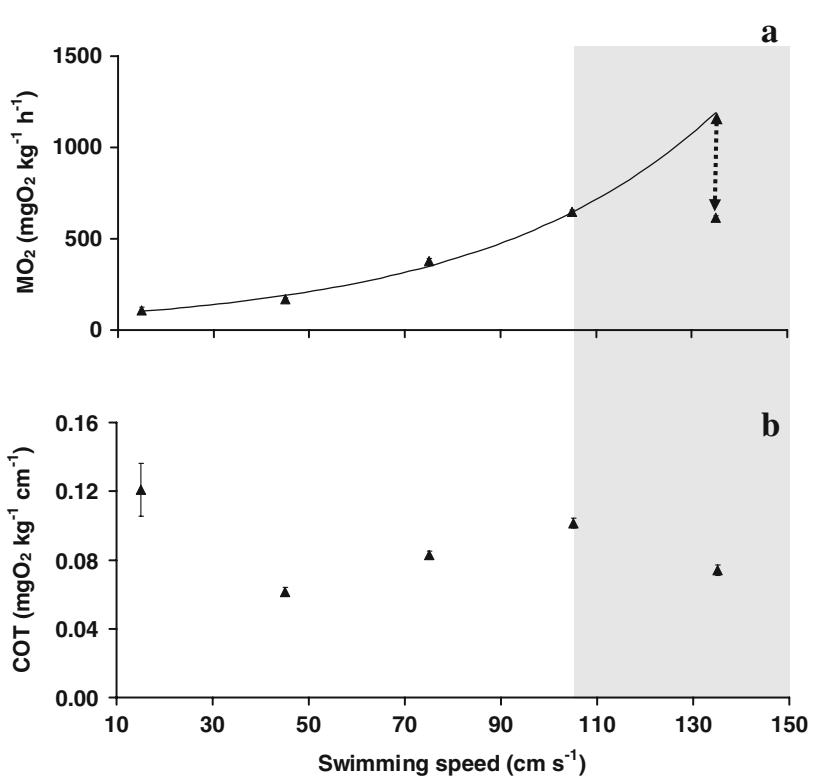

Fig. 1 a Oxygen consumption $\left(\mathrm{MO}_{2}\right)$ as a function of swimming speed $(U)$ during the step protocol test (mean \pm standard error). Solid line indicates exponential curve fitted on $\mathrm{MO}_{2}$ as a function of $\mathrm{U}$ before plateau was attained at $20^{\circ} \mathrm{C}$ (i.e. non shadow area, $\left.\mathrm{MO}_{2}=75.76 \mathrm{e}^{0.020 U}\right)$. Double-arrowed line corresponds to the difference between the experimental values of $\mathrm{MO}_{2}$ and the value of $\mathrm{MO}_{2}$ obtained by extrapolating the exponential curve for the highest speed attained (i.e. $135 \mathrm{~cm} \mathrm{~s}^{-1}$ ). $\mathbf{b}$ Cost of transport (COT) as a function of swimming speed (mean \pm standard error) at $20^{\circ} \mathrm{C}$
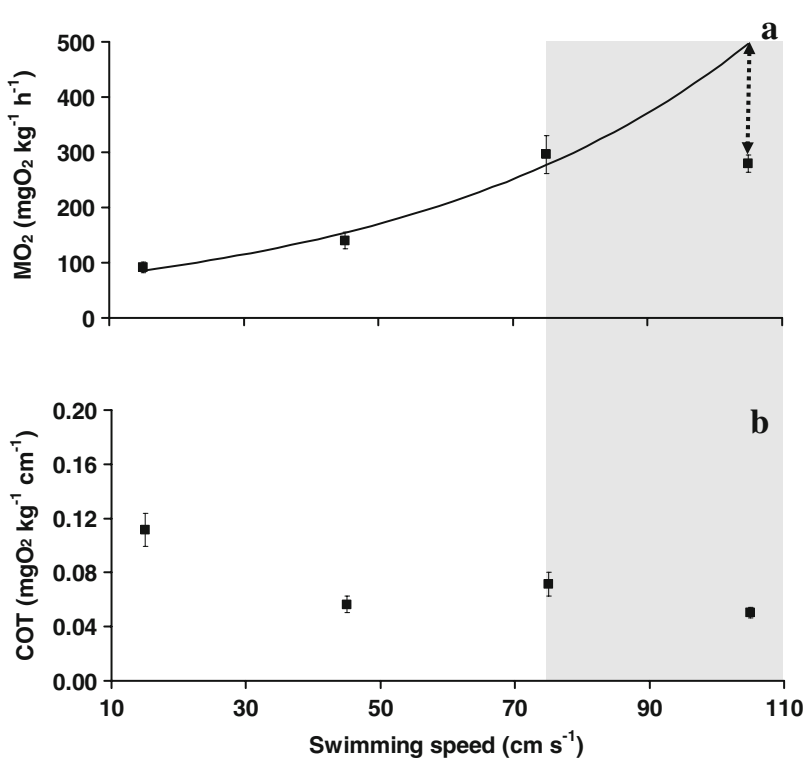

Fig. 2 a Oxygen consumption $\left(\mathrm{MO}_{2}\right)$ as a function of swimming speed $(U)$ during the step protocol test (mean \pm standard error). Solid line indicates exponential curve fitted on $\mathrm{MO}_{2}$ as a function of $U$ before plateau was attained at $30^{\circ} \mathrm{C}$ (i.e. non shadow area, $\left.\mathrm{MO}_{2}=65.12 \mathrm{e}^{0.019 U}\right)$. Double-arrowed line corresponds to the difference between the experimental values of $\mathrm{MO}_{2}$ and the value of $\mathrm{MO}_{2}$ obtained by extrapolating the exponential curve for the highest speed attained (i.e. $105 \mathrm{~cm} \mathrm{~s}^{-1}$ ). b Cost of transport (COT) as a function of swimming speed (mean \pm standard error) at $30^{\circ} \mathrm{C}$

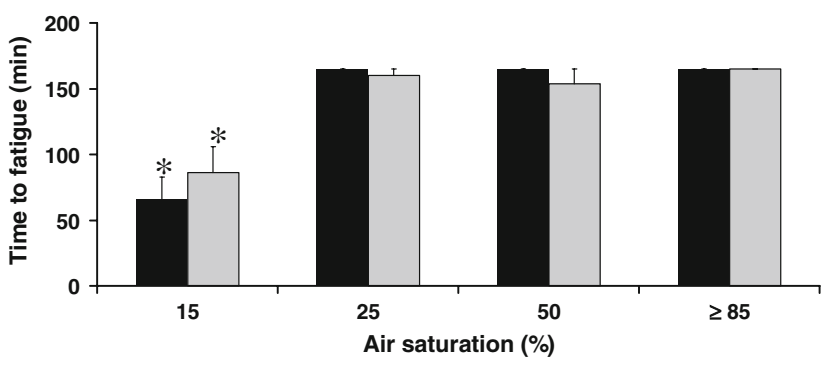

Fig. 3 Time to fatigue $\left(S_{U_{\mathrm{opt}}}\right.$, mean \pm standard error) as a function of oxygen level and temperature. Black and grey histograms represent the mean time to fatigue of flathead grey mullet tested at 20 and $30^{\circ} \mathrm{C}$, respectively. At each experimental temperature, * significant difference from normoxia

higher at 30 than at $20^{\circ} \mathrm{C}$ independent of oxygen level and recovery time (Fig. 4). The oxygen effect was due to a significant elevation of the post-exercise $\mathrm{MO}_{2}$ in fish tested in hypoxia (15\% AS) compared to normoxia (p.c.: $d f=1$, $P<0.001$ for comparison 'normoxia' versus $15 \%$ AS at the different recovery time). Furthermore, oxygen and recovery time interact with each other (Table 1) since the significant effect of recovery time was only observed in fish tested at $15 \%$ AS. In these fish, the $\mathrm{MO}_{2}$ measured immediately after the stamina test (i.e. $\mathrm{MO}_{2-1}$ ) was significantly different from the successive $\mathrm{MO}_{2}$ measured (p.c.: $d f=1, P<0.05$ for each comparison $\mathrm{MO}_{2-1}$ vs. $\mathrm{MO}_{2-2} \mathrm{MO}_{2-3} \mathrm{MO}_{2-4}$ at $15 \%$ AS). At $20^{\circ} \mathrm{C}$, in fish exposed to $15 \%$ AS during the stamina test $\mathrm{MO}_{2-1}$ was $162 \%$ higher than in fish exposed to normoxia (Fig. 4). This difference decreased to $47 \%$ at the end of the recovery period $\left(\mathrm{MO}_{2-4}\right)$. At $30^{\circ} \mathrm{C}$, the pattern was similar (Fig. 4).

\section{Discussion}

Time to fatigue at $U_{\text {opt }}\left(S_{U_{\text {opt }}}\right)$ was not affected by hypoxia down to $\geq 25 \%$ AS, while it was significantly reduced in individuals exposed to $15 \%$ AS at both temperatures

Table 1 Results of the RM ANOVA from the $\mathrm{MO}_{2}$ measured repeatedly in flathead grey mullet after being exposed to four different oxygen levels (normoxia, 50, 25 and 15\% AS) and two temperatures $\left(20\right.$ and $30^{\circ} \mathrm{C}$ ) during a swimming stamina test at $45 \mathrm{~cm} \mathrm{~s}^{-1}$

\begin{tabular}{lllrl}
\hline & Factor & $d f$ & $F$ & $P$ \\
\hline Within & Recovery time & 3 & 63.4 & $<0.001$ \\
Between & Oxygen & 3 & 17.4 & $<0.001$ \\
& Temperature & 1 & 599.6 & $<0.001$ \\
Interaction & Recovery time $\times$ oxygen & 9 & 17.8 & $<0.001$ \\
& Recovery time $\times$ temperature & 3 & 0.5 & $>0.05$ \\
& Temperature $\times$ oxygen & 3 & 0.4 & $>0.05$ \\
\hline
\end{tabular}

One within factor was considered (i.e. recovery time) and two between factors (i.e. oxygen and temperature) 

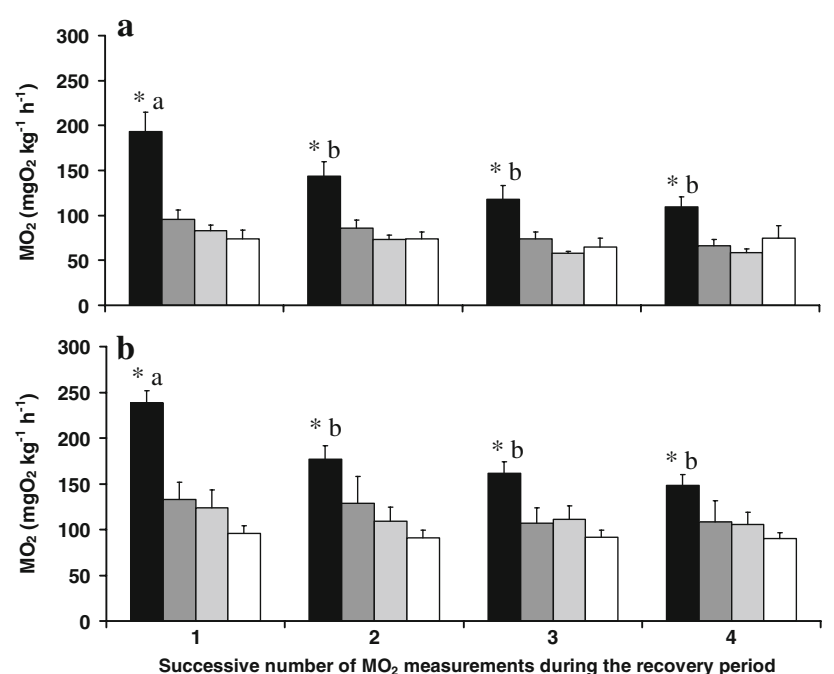

Fig. 4 Post-exercise oxygen consumption $\left(\mathrm{MO}_{2}\right.$, mean \pm standard error) as a function of oxygen level at $20^{\circ} \mathrm{C}$ (a) and $30^{\circ} \mathrm{C}$ (b). 1, 2, 3 and 4 represent the four consecutive measures of $\mathrm{MO}_{2}$ following the stamina test. Black, dark grey, light grey and white histograms represent the mean $\mathrm{MO}_{2}$ of the fish exposed during the stamina test at $15,25,50 \%$ AS and normoxia, respectively. At a given time (1, 2, 3 or 4), * significant difference with normoxia. At $15 \%$ AS, means not sharing a common letter are significantly different from each other

(Fig. 3). Stamina tests were carried out at $U_{\text {opt }}$ estimated to be $45 \mathrm{~cm} \mathrm{~s}^{-1}$ (i.e. $1.12 \mathrm{BL} \mathrm{s}^{-1}$ ). This optimal swimming speed is within the range of the values gathered for 14 teleost species previously studied (reviewed by Videler 1993). The equation relating $U_{\mathrm{opt}}$ to body mass in all these species predicts an optimal speed of $42 \mathrm{~cm} \mathrm{~s}^{-1}$ for a fish of $491.3 \mathrm{~g}$, i.e. the mean weight of the M. cephalus we tested (Videler 1993). While further work is necessary to establish the extent to which fish in general, and flathead grey mullet in particular, use $U_{\text {opt }}$ during their routine activity, the results of the present study unequivocally show that hypoxia can be detrimental for fish activity even when slow swimming speeds are considered.

In fish exposed to hypoxic environment, certain physiological mechanisms are activated in order to maintain the energy capacity (e.g. augmentation of gill ventilation frequency and amplitude, increase of the blood flow in gills, recruitment of branchial gills; Booth 1978, 1979; Itazawa and Takeda 1978; Randall 1982; Maxime and Nonnotte 1997). In our experimental conditions, these adaptations may have been sufficient to maintain the oxygen supply to the organs and tissues in M. cephalus exposed to 25 and $50 \%$ AS. On the other hand, the observed decrease in stamina at $15 \%$ AS suggests that the oxygen supply was no longer enough to maintain aerobic-sustained activity in the muscle powering locomotion during the stamina test. Our results on post-exercise $\mathrm{MO}_{2}$ (following the stamina test) confirm that at $15 \%$ AS, fish metabolism partly shifted from aerobic to anaerobic. Immediately after the test
$\left(\mathrm{MO}_{2-1}\right)$, oxygen consumption recorded in fish tested at $15 \%$ AS was $162 \%$ and $149 \%$ higher than in fish exposed to normoxia at 20 and $30^{\circ} \mathrm{C}$, respectively (Fig. 4). This increase in $\mathrm{MO}_{2}$ is due to the oxygen debt the fish had to repay when oxygen level returns to normoxia. Since the standard metabolic rate (SMR) of $M$. cephalus is not affected by hypoxia as low as $15 \%$ AS (Lefrançois et al., unpublished results), all activities that contribute to standard metabolic rate (e.g. opercular movement, osmoregulation processes) are likely to be sustained aerobically at these low levels of oxygen. Therefore, the anaerobic metabolism at $15 \%$ AS is most likely due to activity that is not included in SMR, i.e. locomotion. Solicitation of anaerobic metabolism to sustain relatively low swimming speeds was observed in various species when exposed to hypoxic conditions (Muusze et al. 1998; Farrell et al. 1998; Herbert and Steffensen 2005). In all these cases, the production of energy through the anaerobic metabolism was induced by systemic hypoxia, due to the rarefaction of the oxygen in the fish external environment. It is also worthwhile to mention that at $15 \%$ AS, the systemic hypoxia may induce a drop of oxygen delivery to the brain, and especially to the central nervous system, thereby affecting the control of locomotion and therefore performance. Furthermore, Peake and Farrell (2006) underline the importance of behavioural regulations in fish performance in swimming tests. They suggested that the fatigue observed in fish tested in a swim flume was due to a behavioural response rather than to physiological exhaustion. Therefore, it is possible that a hypoxia-induced decrease in motivation may also contribute to the low stamina in fish swimming at $15 \%$ AS.

Various studies on M. cephalus (Shingles et al. 2005, Lefrançois et al., unpublished results) or close relatives (Liza aurata, Lefrançois et al. 2005), suggest that Mugilidae have high-anaerobic capacity and are hypoxia tolerant, compared to other species. In the present study, highanaerobic capacity is suggested by the relatively large difference (78 and $93 \%$ at 20 and $30^{\circ} \mathrm{C}$, respectively) between the measured oxygen consumption in $M$. cephalus near exhaustion and values obtained from extrapolating the exponential curve (see Figs. 1, 2). The exponential curves were fitted at lower swimming speeds (aerobically powered) and their extrapolation allows predicting the oxygen cost of swimming to exhaustion. As discussed before, the presence of a plateau near exhaustion suggests that swimming effort at those speeds is powered anaerobically. The difference between the plateau and the estimated oxygen cost may be considered as an indirect indicator of the anaerobic power needed to sustain the swimming effort and, therefore, relative considerations on the type of metabolism employed by the fish need to be taken with caution. Nevertheless, this difference appear to be much 
larger than that found in other, less hypoxia tolerant, species such as sockeye salmon $(51 \%$, based on Lee et al. 2003b). Therefore, we suggest that in M. cephalus, thrust power to achieve relatively high speed can be greatly supplemented by anaerobic metabolism/white muscle, as shown in hypoxia-tolerant species such as carp (Jones 1982; Hammer 1995).

High hypoxia tolerance in adult M. cephalus is suggested in various studies. Shingles et al. (2005) show that M. cephalus did not lose their balance at oxygen level as low as $10 \%$ AS. Work on antipredator response also shows high hypoxia tolerance in Mugilidae compared to other species. When exposed to a startled stimulus, golden grey mullet (Liza aurata) showed a disorientation only at oxygen level as low as $20 \%$ AS (i.e. a significant proportion of the fish initially escaped in the direction of the stimulus), while sea bass (Dicentrarchus labrax), a species that is less tolerant to hypoxia, showed a disorientation when oxygen level was 50\% AS (Lefrançois et al. 2005; Lefrançois and Domenici 2006). Since our work showed an effect of severe hypoxia on low-speed locomotion in a highly tolerant species, it is possible that hypoxic conditions less severe than those tested here may reduce stamina at low speed in less tolerant species such as sea bass.

Free swimming $M$. cephalus may also respond to severe hypoxia with a number of behavioural strategies. Swimming speed could be reduced, thereby reducing oxygen requirements and mitigating the negative effects of hypoxia. However, reduced speed could be detrimental, since reducing activity by swimming at low speeds $<U_{\text {opt }}$ would increase the aerobic cost of transport. In addition, reduced activity would decrease habitat exploration and therefore opportunities to find food, to encounter conspecifics and to find better oxygen conditions. At more extreme levels, fish may remain motionless, further reducing their habitat exploration. It is worth noticing that, in nature, changes in swimming activity may be the result of a trade-off between (1) swimming under partially anaerobic metabolic conditions associated with the energy gained when grazing on low-energy content food (e.g. organic matter or microphytobenthos) and (2) remaining motionless, thus avoiding anaerobism but also not being able to forage. Flathead grey mullets can also mitigate the effects of hypoxia by performing aquatic surface respiration (ASR), through which they breath the highly oxygenated water at the surface layer (Shingles et al. 2005). In various species of Mugilidae, ASR is triggered at oxygen saturations near $10-15 \%$ AS (R.S. Ferrari et al. submitted, $60 \%$ of the fish performing ASR at $10 \%$ AS Shingles et al. 2005). In our experiments, flathead grey mullets could not perform ASR because of experimental constraints since they did not have access to the water/air interface in the swimming respirometer. It is possible that when encountering hypoxic conditions in nature, flathead grey mullet may choose to swim near the surface, performing ASR (Domenici and Lefrancois, personal observations). By doing so, they may partly mitigate the solicitation of anaerobic metabolism. However, swimming with the mouth open near the surface is likely to have a number of detrimental effects, such as increase in drag, loss of feeding opportunities (grey mullets tend to be bottom feeders), and exposure to predators (Domenici et al. 2007). Therefore, while potentially grey mullet may be able to mitigate the effects of hypoxia using a number of behavioural strategies, these strategies would invariably imply a cost.

In conclusion, since hypoxia was found to affect the low swimming performance in a hypoxia tolerant species, we suggest that testing stamina at these speeds may be relevant in order to assess the effect of hypoxia on behavioural activities carried out at low speed, such as food searching.

Acknowledgments Financial support by the European Union, Directorate Fisheries, through contract QLRS-2002-00799 (project ETHOFISH) is acknowledged. Experiments carried out in this work comply with the current regulations in Italy (no. 116/1992).

\section{References}

Booth JH (1978) The distribution of blood flow in the gills of fish: application of a new tecnique to rainbow trout (Salmo gairdneri). J Exp Biol 73:119-129

Booth JH (1979) The effects of oxygen supply, epinephrine and acetylcholine on the distribution of blood flow in the trout gills. J Exp Biol 83:31-39

Brett JR (1964) The respiratory metabolism and swimming performance of young sockeye salmon. J Fish Res Bd Can 21:11831226

Brett JR (1965) The relation of size to rate of oxygen consumption and sustained swimming speed of sockeye salmon (Oncorhynchus nerka). J Fish Res Bd Can 22:1491-1501

Bushnell PG, Steffensen JF, Johansen K (1984) Oxygen consumption and swimming performance in hypoxia-acclimated rainbow trout Salmo gairdneri. J Exp Biol 113:225-235

Claireaux G, Lefrançois C (2007) Linking environmental variability and fish performance: integration through the concept of scope for activity. Philos Trans R Soc 362(1487):2031-2041. doi: 10.1098/rstb.2007.2099

Domenici P (2003) Habitat type, design and the swimming performance of fish. In: Bels V, Gasc JP, Casinos A (eds) Vertebrate biomechanics and evolution. Bios Scientific Publishers, Oxford, pp $137-160$

Domenici P, Blake RW (1993) The effect of size on the kinematics and performance of angelfish (Pterophyllum eimekei) escape responses. Can J Zool 71:2319-2326

Domenici P, Lefrançois C, Shingles A (2007) Hypoxia and the antipredator behaviours of fishes. Philos Trans R Soc 362(1487): 2105-2121. doi:10.1098/rstb.2007.2103

Farrell AP, Gamperl AK, Birtwell IK (1998) Prolonged swimming, recovery and repeat swimming performance of mature sockeye salmon Oncorhynchus nerka exposed to moderate hypoxia and pentachlorophenol. J Exp Biol 201:2183-2193 
Ferrari RS, Moreira da Silva J, Lefrançois C, Domenici P (submitted) The Effect of progressive hypoxia on the spontaneous activity in single and grouped golden grey mullet, Liza aurata. J Fish Biol

Fry FE (1971) The effect of environmental factors on the physiology of fish. In: Hoar, Randall D (eds) Fish physiology, vol VI. Academic press, New York, pp 1-98

Gallaugher PE, Thorarensen H, Kiessling A, Farrell AP (2001) Effects of high intensity exercise training on cardiovascular function, oxygen uptake, internal oxygen transport and osmotic balance in Chinook salmon (Oncorhynchus tshawytscha) during critical speed swimming. J Exp Biol 203:2861-2872

Ghalambor CK, Reznick DN, Walker JA (2004) Constraints on adaptative evolution: the functional trade-off between reproduction and fast start swimming performance in the Trinidadian guppy (Poecilia reticulata). Am Nat 164(1):38-50. doi:10.1086/ 421412

Hammer C (1995) Fatigue and exercise tests with fish. Comp Biochem Physiol 112A(1):1-20. doi:10.1016/0300-9629(95) 00060-K

Herbert NA, Steffensen JF (2005) The response of Atlantic cod, Gadus morhua, to progressive hypoxia: fish swimming speed and physiological stress. Mar Biol (Berl) 147:1403-1412. doi: 10.1007/s00227-005-0003-8

Hinch SG, Rand PS (2000) Optimal swim speeds and forward assisted propulsion: energy conserving behaviours of up-river migrating salmon. Can J Fish Aquat Sci 57:2470-2478. doi:10.1139/ cjfas-57-12-2470

Itazawa Y, Takeda T (1978) Gas exchange in the carp gills in normoxic and hypoxic conditions. Respir Physiol 35:263-269. doi:10.1016/0034-5687(78)90002-6

Jones DR (1982) Anaerobic exercise in teleost fish. Can J Zool 60:1131-1134

Kutty MN (1968) Influence of ambient oxygen on the swimming performance of goldfish and rainbow trout. Can J Zool 46:647653

Lee CG, Farrell AP, Lotto A, MacNutt MJ, Hinch SG, Healey MC (2003a) The effect of temperature on swimming performance and oxygen consumption in adult sockeye (Oncorhynchus nerka) and coho $(O$. kisutch) salmon stocks. J Exp Biol 206:3239-3251. doi: $10.1242 /$ jeb.00547

Lee CG, Farrell AP, Lotto A, Hinch SG, Healey MC (2003b) Excess post-exercise oxygen consumption in adult sockeye (Oncorhynchus nerka) and coho (O. kisutch) salmon following critical speed swimming. J Exp Biol 206:3253-3260. doi:10.1242/jeb. 00548

Lefrançois C, Claireaux G (2003) Influence of ambient oxygenation and temperature on metabolic scope and scope for heart rate of the sole (Solea solea). Mar Ecol Prog Ser 259:273-284. doi: $10.3354 /$ meps 259273

Lefrançois C, Shingles A, Domenici P (2005) The effect of hypoxia on locomotor performance and behaviour during escape in the golden grey mullet (Liza aurata). J Fish Biol 67:1711-1729. doi: 10.1111/j.1095-8649.2005.00884.x
Lefrancois C, Domenici P (2006) Locomotor kinematics and responsiveness in the escape behaviour of European sea bass (Dicentrarchus labrax) exposed to hypoxia. Mar Biol (Berl) 149(4):969-977. doi:10.1007/s00227-006-0261-0

Maxime V, Nonnotte G (1997) Bases physiologiques de la respiration chez les poissons. Piscic Fr 129:1-25

Muusze B, Marcon J, vandenThillart G, Almeida-Val VMF (1998) Hypoxia tolerance of Amazon fish. Respirometry and energy metabolism of the cichlid Astronotus ocellatus. Comp Biochem Physiol 120(A):151-156

Peake SJ, Farrell AP (2006) Fatigue is a behavioural response in respirometer-confined smallmouth bass. J Fish Biol 68:17421755. doi:10.1111/j.0022-1112.2006.01052.x

Quinn GP, Keough MJ (2002) Experimental design and data analysis for biologists. Cambridge University Press, Cambridge

Randall D (1982) The control of respiration and circulation in fish during exercise and hypoxia. J Exp Biol 100:275-288

Schurmann H, Steffensen JF (1994) Spontaneous swimming activity of Atlantic cod Gadus morhua exposed to graded hypoxia at three temperatures. J Exp Biol 197:129-142

Shingles A, McKenzie DJ, Claireaux G, Domenici P (2005) Reflex cardioventilatory responses to hypoxia in the flathead grey mullet (Mugil cephalus) and their behavioural modulation by perceived threat of predation and water turbidity. Physiol Biochem Zool 78(5):744-755. doi:10.1086/432143

Thorarensen H, Gallaugher PE, Kiessling AK, Farrell AP (1993) Intestinal blood flow in swimming chinook salmon Oncorhynchus tshawytscha and the effects of haematocrit on blood flow distribution. J Exp Biol 179:115-129

Tucker VA (1970) Energetic cost of locomotion in animals. Comp Biochem Physiol 34:841-846. doi:10.1016/0010-406X(70) 91006-6

Underwood AJ (1981) Techniques of analysis of variance in experimental marine biology and ecology. Oceanogr Mar Biol Annu Rev 19:513-605

Videler J (1993) Ecological implications. In Fish swimming. Chapman, Hall (eds): 207-226

Webb PW (1975) Acceleration performance of rainbow trout (Oncorhynchus mykiss). J Exp Biol 63:451-465

Webb PW (1977) Effects of size on performance and energetics of fish. In: Pedley TJ (ed) Scale effects in animal locomotion. Academic Press, New York, pp 315-331

Webb PW, Gerstner CL (2000) Fish swimming behaviour: predictions from physical principles. In: Domenici P, Blake R (eds) Biomechanics in animal behaviour. Bios Scientific Publishers, Oxford, pp 59-77

Webb PW, Kostecki PT, Stevens ED (1984) The effect of size and swimming speed on locomotor kinematics of rainbow trout. J Exp Biol 109:77-95

Weihs D (1973) The mechanism of rapid starting of slender fish. Biorheology 10:343-350 